\title{
O Desafio do Planejamento Estratégico em Arranjos Produtivos Locais: O Plano de Desenvolvimento do APL Agroindústria Familiar da Região Celeiro-RS'
}

\author{
DAVID BASSO \\ Universidade Regional do Noroeste do Estado do Rio \\ DILSON TRENNEPOHL \\ Universidade Regional do Noroeste do Estado do Rio \\ JOSÉ VALDEMIR MUENCHEN \\ Universidade Regional do Noroeste do Estado do Rio \\ TIAGO REGINALDO ZAGONEL \\ Universidade Regional do Noroeste do Estado do Rio
}
1 Uma versão deste trabalho foi apresentada e consta dos anais do IX Encontro de Estudos sobre Empreendedoris mo e Gestão de
Pequenas Empresas (EGEPE), realizado em Passo Fundo-RS de 16 a 18 de março de 2016.

\section{Resumo}

O estímulo à constituição de arranjos produtivos tem sido uma política de governos do Rio Grande do Sul para enfrentar as vulnerabilidades do desenvolvimento nas diferentes regiões do Estado. $O$ objetivo deste trabalho é apresentar estratégias e ações para o plano de desenvolvimento do APL Agroindústria Familiar da Região Celeiro a partir de um diagnóstico sobre a região e o APL. O diagnóstico levou em consideração dados secundários sobre a região e, em especial, dados primários gerados a partir de observações diretas e entrevistas semiestruturadas com responsáveis por todas as organizações diretamente ligadas ao arranjo e lideranças locais. Apesar do uso de dados quantitativos, o estudo segue uma abordagem qualitativa baseada principalmente na interpretação das informações coletadas e geradas. A construção do plano de desenvolvimento seguiu uma metodologia participativa e estratégica, com efetivo envolvimento dos atores locais para estabelecer uma visão partilhada sobre os rumos do desenvolvimento, bem como a definição das ações necessárias para atingi-lo. Os resultados reforçam seis estratégias, cada uma com um conjunto de ações, no sentido de reforçar o arranjo local como uma alternativa para enfrentar os problemas sociais e econômicos da região.

Palavras-chave: Arranjos Produtivos Locais. Desenvolvimento Regional. Planejamento Estratégico. 


\title{
The Challenge of Strategic Planning in Local Productive Arrangements: The Development Plan of the APL Family Agroindustry of the Região Celeiro-RS
}

\begin{abstract}
Abstract: The stimulus to the constitution of productive arrangements has been a policy of governments of Rio Grande do Sul to confront the vulnerabilities of development in the different regions of the state. The objective of this work is to present strategies and actions for the development plan of APL Agroindústria Familiar da Região Celeiro based on a diagnosis about the region and the APL. The diagnosis took into account secondary data on the region and, in particular, primary data generated from direct observations and semistructured interviews with those responsible for all organizations directly linked to the arrangement and local leaderships. Despite the use of quantitative data, the study follows a qualitative approach based mainly on the interpretation of the information collected and generated. The construction of the development plan followed a participatory and strategic methodology, with effective involvement of the local actors to establish a shared vision about the direction of development, as well as the definition of the actions necessary to reach it. The results reinforce six strategies, each with a set of actions, in order to reinforce the local arrangement as an alternative to face the social and economic problems of the region.
\end{abstract}

Keywords: Local Productive Arrangements. Regional development. Strategic planning.

\section{El Desafío de la Planificación Estratégica en Arreglos Productivos Locales: El Plan de Desarrollo del APL Agroindustria Familiar da Região Celeiro-RS}

\section{Resumen}

El estímulo a la constitución de arreglos productivos ha sido una política de gobiernos de Rio Grande do Sul para enfrentar las vulnerabilidades del desarrollo en las diferentes regiones del estado. El objetivo de este trabajo es presentar estrategias y acciones para el plan de desarrollo del APL Agroindustria Familiar da Região Celeiro a partir de un diagnóstico sobre la región y el APL. El diagnóstico tuvo en cuenta datos secundarios sobre la región y, en particular, datos primarios generados a partir de observaciones directas y entrevistas semiestructuradas con responsables de todas las organizaciones directamente ligadas al arreglo y liderazgos locales. A pesar del uso de datos cuantitativos, el estudio sigue un abordaje cualitativo basado principalmente en la interpretación de las informaciones recolectadas y generadas. La construcción del plan de desarrollo siguió una metodología participativa y estratégica, con participación efectiva de los actores locales para establecer una visión compartida sobre los rumbos del desarrollo, así como la definición de las acciones necesarias para alcanzarlo. Los resultados refuerzan seis estrategias, cada una con un conjunto de acciones, en el sentido de reforzar el arreglo local como una alternativa para enfrentar los problemas sociales y económicos de la región.

Palabras clave: Arreglos Productivos Locales. Desarrollo Regional. Planificación Estratégica.

\section{INTRODUÇÃO}

O Arranjo Produtivo Local Agroindústria Familiar da Região Celeiro-RS-APL Celeiro é representado por um conjunto de agentes econômicos, políticos e sociais localizados nos municípios que compõem a Região Celeiro, situada no Noroeste do Estado do Rio Grande do Sul. 
O APL Celeiro, centrado na agroindústria familiar, em especial na cadeia produtiva do leite, inclui os produtores rurais organizados em cooperativas familiares e sua articulação com empresas produtoras de bens e serviços finais, fornecedoras de equipamentos e outros insumos, prestadoras de serviços, comercializadoras, clientes e outras cooperativas, associações e organizações voltadas à formação e treinamento, informação, pesquisa, promoção e financiamento. A articulação conjunta destes atores e o aproveitamento das sinergias geradas por suas interações fortalecem as chances de sobrevivência e crescimento, constituindo-se em importante fonte de vantagens competitivas duradouras.

Articulado e coordenado pela Associação Gaúcha de Empreendimentos Lácteos (AGEL) trata-se de um patrimônio construído pela comunidade local, com forte sentimento recíproco de pertencimento e reconhecimento e também meio para geração de empregos, rendas, bem-estar e valorização cultural, social e ambiental.

Este estudo tem por objetivo apresentar estratégias e ações para o desenvolvimento do APL Celeiro a partir de um diagnóstico sobre a região e o funcionamento do APL. O diagnóstico levou em consideração dados secundários sobre a região e, em especial, dados primários gerados sobre o APL a partir de observações diretas e entrevistas semiestruturadas com responsáveis por todas as organizações diretamente ligadas ao Arranjo e lideranças locais. Mesmo tendo se utilizado de muitos dados quantitativos, tanto secundários, coletados em bancos de dados (IBGE, FEE, APL Celeiro), quanto primários, gerados a partir das entrevistas, o estudo segue uma abordagem qualitativa baseada principalmente na interpretação das informações coletadas e geradas.

A construção do Plano de Desenvolvimento seguiu uma metodologia participativa e estratégica, com efetivo envolvimento dos atores locais para estabelecer uma visão partilhada quanto ao rumo a ser tomado pelo desenvolvimento, bem como a definição das ações necessárias para atingi-lo. Assim, tanto a metodologia quanto o processo de elaboração do Plano de Desenvolvimento incluíram a realização de discussões conjuntas com os atores locais que fazem parte do APL Celeiro, em diferentes fases de sua construção.

Além desta introdução, o estudo destaca um conjunto de supostos teóricometodológicos que nortearam a elaboração do Plano. Na sequência, apresenta-se uma síntese do diagnóstico produzido sobre o APL Celeiro. Com base no diagnóstico, então, destaca-se um conjunto de estratégias e ações que foram propostas para o desenvolvimento do APL e da região. Por fim, ressaltam-se as considerações finais do estudo.

\section{Supostos Teórico-Metodológicos que orientaram o Processo de Elaboração do Plano de Desenvolvimento do APL Celeiro}

O planejamento estratégico, desenvolvido no âmbito institucional, consiste em um processo gerencial que visa estabelecer a melhor relação possível entre a organização e seu ambiente. Nesse sentido, o planejamento estratégico abrange a definição da missão e dos objetivos institucionais, partindo de uma análise ampla do ambiente interno e externo da organização. Desenvolve-se numa perspectiva de 
longo prazo, partindo de uma abordagem global que envolve a empresa como um todo integrado de recursos, capacidades e potencialidades. Nesse tipo de planejamento, os administradores tomam decisões baseadas muito mais em julgamentos e escolhas do que em dados técnicos.

O planejamento é um processo de análise da realidade e de posicionamento estratégico central na gestão de organizações públicas e privadas que vem sendo aprimorado a partir de novos referenciais de leitura e monitoramento do ambiente organizacional. O planejamento estratégico, por sua vez, pode ser tomado como um processo permanente de definição e redefinição da própria identidade institucional, de seus objetivos estruturantes, das metas prioritárias, das estratégias escolhidas para empreender ações e empenhar meios e esforços para alcançá-los, em interação com as circunstâncias do ambiente em que estão inseridas.

A política de apoio ao desenvolvimento de APLs no Rio Grande do Sul remonta aos anos 1990, sendo precursora da ação dirigida aos arranjos em nível nacional pelo governo federal. Em 1999, o governo do Estado, por intermédio de sua Secretaria do Desenvolvimento e Assuntos Internacionais - Sedai, criou o Programa de Apoio aos Sistemas Locais de Produção. Assim, iniciou e foi formalizada uma política estadual voltada para desenvolvimento regional com base nos APLs. Os diferentes governos gaúchos deram seguimento no apoio às aglomerações produtivas, com ênfases e nomenclaturas diversas (TATSCH et al, 2011).

As características da economia gaúcha, especialmente no que se refere à concentração regional de cadeias produtivas e à existência de uma rede de instituições de ensino, de pesquisa e de apoio às organizações, potencializou a estratégia de promoção do desenvolvimento regional por meio do incremento de APLs, dinamizando a matriz produtiva existente, fomentando novos investimentos estratégicos e apoiando a organização de atividades associativas (CASTILHOS, 2002).

O Programa de Fortalecimento das Cadeias dos Arranjos Produtivos Locais tem se constituído um dos eixos fundamentais da política de desenvolvimento do Estado para elevar a competitividade das empresas, incentivar a Economia da Cooperação, atenuar desequilíbrios regionais, ambientais e sociais e contribuir para o desenvolvimento sustentável e harmônico do Rio Grande do Sul (MUCKE, 2012). Ainda segundo Mucke (2012), a Política Estadual de Fomento à Economia da Cooperação institucionaliza objetivos comuns a diversos programas, buscando sinergias e eficiência, definindo instrumentos comuns e, com isso, permite que a execução de ações e instrumentos de política pública fortaleçam a cooperação institucional e a capacidade de geração endógena de fatores dinâmicos do desenvolvimento local.

A finalidade da adoção do planejamento estratégico é a busca de um sentido de direção futura, por meio do maior conhecimento de realidades específicas, mediante um maior conhecimento de fatores externos não controláveis e de fatores internos controláveis. O homem é um ser político por natureza e nenhuma atividade humana deve ser desenvolvida sem considerar as suas implicações políticas, ou seu impacto sobre a sociedade. Existe uma íntima relação entre técnica e política no planejamento, destacando que a oposição atribuída entre eles resulta da falta de entendimento mútuo entre os diferentes participantes no processo decisório e na suposição de que as duas partes sejam incompatíveis. Para que um 
sistema de planejamento consiga envolver simultaneamente as dimensões técnica e política, é necessário que o mesmo seja construído em bases democráticas, evitando os excessos de tecnocracia, totalitarismo e instabilidade política, características frequentes de países em desenvolvimento (BASSO; TRENNEPOHL, 2014).

As dificuldades com as quais as sociedades se defrontam nos seus processos de desenvolvimento colocam aos planejadores um papel político fundamental. Eles terão de apontar para uma transformação concreta da realidade, na construção de uma sociedade com oportunidades amplas para os cidadãos. A tecnologia cresce rapidamente, impondo mudanças nos hábitos sociais, de forma não planejada e gerando problemas sociais e ambientais não esperados. Sendo assim, do ponto de vista ético e político, é importante que os planejadores coloquem a sustentabilidade do desenvolvimento em suas pautas de discurso e prática de planejamento.

Demo (1993) fala sobre o perigo de manifestação da propensão tecnocrática no poder do técnico e acrescenta que a tendência tecnocrática está ligada à falsa dicotomia entre teoria e prática e entre trabalho manual e trabalho intelectual. $O$ planejamento, segundo Demo (1993), deve estar investido de qualidade política, enfatizando os conteúdos do planejamento antes de considerar os métodos. Gross (1982) complementa destacando a necessidade do desenvolvimento de um estilo humanista de aprendizagem por meio do planejamento e uma teoria de planejamento envolvendo um amplo conhecimento da sociedade, para só assim escapar ao domínio do planejamento tecnocrático.

Bustelo (1982), por sua vez, destaca no planejamento o conceito de viabilidade política que só pode ser alcançada por meio da negociação franca entre os diversos participantes do sistema tomado como unidade a ser planejada. Ao apresentar as bases para o planejamento e políticas sociais, o autor destaca conceitos como a flexibilidade, a participação, a democracia, a viabilidade política, a negociação, os processos não lineares e a progressividade na distribuição que devem ser utilizados e repetidos até a exaustão.

Se o planejamento estratégico é esse processo através do qual uma organização se mobiliza para construir seu futuro por meio de um comportamento proativo, considerando o ambiente atual e futuro, então deve começar pela identificação do sujeito que está realizando o seu planejamento. Qual é a natureza da organização em foco? Trata-se de uma pessoa, de uma família, de uma empresa pública ou privada, de um órgão público ou de entidades organizativas de tais agentes? Compreender claramente a natureza da entidade que pretende fazer seu planejamento é o primeiro passo (BUSTELO, 1982).

A Rede de Pesquisa em Sistemas Produtivos e Inovativos Locais/ Universidade Federal do Rio de Janeiro - RedeSist/UFRJ define APLs como aglomerações de empresas, localizadas em um mesmo território, que apresentam especialização produtiva e mantêm vínculos de articulação, interação, cooperação e aprendizagem entre si e com outros atores locais, tais como: governo, associações empresariais, instituições de crédito, ensino, pesquisa e outras. A ideia chave é a de que a aglomeração espacial de empresas em torno de uma atividade produtiva, com divisão e especialização do trabalho, produz ganhos de competitividade às empresas por meio da eficiência coletiva, derivada da conjunção entre as economias externas e as de cooperação entre os agentes locais (LASTRES; CASSIOLATO, 2005). 
Segundo Lastres e Cassiolato (2005), economias de aglomeração são definidas como o conjunto de externalidades positivas que surgem pela concentração espacial de empresas vinculadas a uma mesma cadeia produtiva, incluindo, dentre outros: amplo contingente de mão de obra especializada e com habilidades específicas ao sistema local; presença e atração de fornecedores especializados; disseminação de conhecimentos, habilidades e informações por meio de contatos interpessoais, interações frequentes entre empresas, mobilidade da força de trabalho entre as empresas, operações em rede, novos negócios, universidades, centros de pesquisa e demais instituições locais, devido à proximidade geográfica entre os participantes do aglomerado; criação de um ambiente favorável ao surgimento de inovações, ao desenvolvimento tecnológico e à melhora da dinâmica econômica de empresas e da região como um todo; maior viabilidade para a instalação de instituições que ofertem serviços específicos à atividade produtiva local nos campos do ensino, treinamento e capacitação, da pesquisa e desenvolvimento tecnológico, da propaganda e marketing, da metrologia e certificação; maior viabilidade para a realização de investimentos em infraestrutura. Destaca-se igualmente a existência de fatores geradores de externalidades positivas específicos ao território, envolvendo não somente recursos naturais, mas especialmente as relações estabelecidas entre os atores, gerando confiança que se traduz na redução de custos de transação, transmissão de conhecimentos tácitos e em aumento da cooperação.

No que tange aos ganhos inerentes à cooperação, as relações de governança local que se instituem no APL podem aumentar a eficiência coletiva e a competitividade das empresas por meio de ações, tais como: compras, vendas, exportações, distribuição e promoção comercial em conjunto; cooperativas de crédito, fundos e sociedades garantidoras de crédito; cursos de capacitação gerencial e formação profissional; contratação de serviços especializados; estabelecimento de centros tecnológicos de uso coletivo; utilização em conjunto de máquinas e equipamentos; marcas, certificados de origem e publicidade de uso coletivo; desenvolvimento/adoção de tecnologias da informação e softwares de uso coletivo; compartilhamento de inteligência financeira, contábil e de controle; investimentos conjuntos para superar problemas de infraestrutura.

Essas relações de governança local são resultado da frequente interação entre os atores, que criam uma cultura e relações de liderança locais, que produzem regras informais que regulam, delimitam, controlam e sancionam a cooperação entre empresas e destas com as demais instituições. As relações de governança estabelecem como são tomadas as decisões e como é desencadeada a ação em face aos desafios comuns enfrentados pelo APL. Essas relações tendem a organizar e a tornar mais eficientes a especialização do trabalho e as ações de cooperação entre os agentes, além de diminuir a competição predatória, aumentando a eficiência de cada empresa e coletiva do Arranjo. Muitas das vantagens que empresas de grande porte obtêm por produzirem em larga escala podem ser alcançadas por empresas de micro e pequeno portes quando localizadas em grande número e em proximidade geográfica, sem que haja perda de flexibilidade, graças à conjunção das economias de aglomeração com as de cooperação (BECATTINI, 1991).

$\mathrm{O}$ argumento fundamental da RedeSist é que, apesar de relevante, a análise da empresa individual é insuficiente para captar processos complexos. Segundo Lastres e Cassiolato (2005), a criação de capacitações deve ser uma preocupação 
permanente e entendida sistematicamente. Como as organizações estão enraizadas em territórios particulares, o importante é analisar o conjunto de agentes que se relacionam e dependem uns dos outros, bem como seus específicos contextos econômico e sociopolítico, visando captar a forma e a intensidade das interações, não só as que se estabelecem entre as empresas ou entre as diversas unidades de cada uma delas, mas também as que são estabelecidas entre as empresas e outras organizações de ensino e pesquisa, promoção, financiamento, etc.

As ligações de interdependência, interação e cooperação, no entanto, "não são captadas pelas estatísticas disponíveis, que geralmente focalizam especialmente organizações e municípios" (LASTRES; CASSIOLATO, 2005, p. 12). Por conta disso, a observação direta da realidade torna-se um procedimento metodológico fundamental tanto para conhecer e explicar quanto para propor ações voltadas ao desenvolvimento de arranjos produtivos locais.

O objetivo de se identificar a contextualização e caracterização do APL é o de formar um ponto de partida, diagnosticar a situação atual para poder identificar o que pode ou deve ser mudado. Para tanto, torna-se necessário recuperar o processo histórico de constituição do APL na região, incluindo a identificação dos atores, as formas como eles interagem e cooperam entre si, as relações de governança entre os atores e do próprio Arranjo. Adicionalmente, é importante mapear os diversos aspectos relacionados à infraestrutura, políticas públicas, ações do poder público (municipal, estadual e federal), bem como dados das empresas e do mercado de trabalho.

No tocante ao aspecto estratégico, deve-se levar em conta a necessidade da utilização de um referencial que seja capaz de se coadunar com a dimensão participativa do plano. O marco referencial sugerido para nortear a visão estratégica na formulação dos Planos de Desenvolvimento é o Planejamento Estratégico Situacional - PES, desenvolvido pelo chileno Carlos Matus, caracterizado como um método do tipo sistêmico e contínuo, buscando perceber a realidade de forma situacional, ampla, dinâmica e profunda. Para Matus (1996), o ator está inserido em uma realidade concreta onde existem outros atores sociais, inclusive oponentes, que também planejam. Assim, no enfoque situacional, o planejamento é realizado por atores que têm interesses específicos, explicações diferentes da realidade e cada perspectiva estará marcada, condicionada e limitada pela inserção particular de cada ator.

A perspectiva proposta por Matus (1996) converge com o posicionamento metodológico assumido pela equipe técnica responsável pela elaboração do Plano de Desenvolvimento APL Celeiro, que se fundamenta em alguns princípios como os destacados a seguir.

O desenvolvimento deve ser visto como um processo evolutivo, mas, ao mesmo tempo, aberto e, por consequência, de difícil previsibilidade. Para explicar de forma mais coerente possível uma realidade ou situação concreta de desenvolvimento, precisa-se, portanto, compreendê-la e o caminho mais adequado para isso é a aproximação, a observação, o contato direto (BASSO; MUENCHEN, 2006; SILVA NETO, 2007; SILVA NETO; BASSO, 2010; BASSO, 2012). Aproximar-se progressivamente do objeto real de estudo para compreendê-lo em maior profundidade requer um procedimento adequado de pesquisa.

O estudo ou pesquisa deve se concentrar inicialmente nos aspectos mais gerais da realidade a ser estudada, só passando a aspectos mais específicos após 
uma síntese que permita formular quais são as variáveis mais pertinentes a serem analisadas, ou questões mais importantes a serem respondidas, no nível imediatamente inferior. Tal síntese é efetuada pela organização e análise da coerência das informações obtidas, sendo retidas apenas aquelas consideradas imprescindíveis para explicar a realidade observada, e não apenas para descrevê-la, no nível de abrangência em questão.

Para compreender a situação estudada e ter boas condições de explicá-la, o pesquisador deve privilegiar o contato direto com a realidade. A partir de observações e falas com interlocutores selecionados, deve-se analisar cada etapa de estudo progressivamente, procurando responder apenas as questões que parecem ser as mais pertinentes para cada etapa. No momento em que as principais questões relativas àquele nível foram respondidas de forma satisfatória, realiza-se uma síntese que permita identificar questões relevantes para orientar a análise a ser efetuada no nível posterior. Concentrando-se nas informações com maior poder explicativo, pode-se, progressivamente, formular uma explicação do objeto de estudo no nível de detalhe desejado de forma eficiente e rigorosa (SILVA NETO, 2007). Cada objeto de estudo ou faceta de uma realidade que se queira investigar envolve níveis de estudo particulares e procedimentos específicos. Para atender aos princípios metodológicos anunciados anteriormente, contudo, pode-se dividir qualquer análise de situação de desenvolvimento em pelo menos três grandes níveis ou etapas de estudo (BASSO, 2012).

O primeiro nível ou etapa contempla uma caracterização do processo de desenvolvimento ou evolução da região onde se localiza a situação ou objeto que está sendo investigado. O segundo nível ou etapa envolve a definição de tipologias de atores ou agentes econômicos, sociais, políticos, dependendo do foco de cada investigação, decorrentes dos processos de diferenciação identificados na análise histórica feita na etapa anterior. Se a investigação envolve empresas, ramos ou setores de produção, esta etapa inclui também uma caracterização técnica e econômica dos sistemas produtivos com a finalidade de observar a sua capacidade de reprodução social ou sustentabilidade ao longo do tempo. O terceiro nível ou etapa contempla a definição de linhas estratégicas de desenvolvimento, visando melhorar as condições de reprodução social tanto do ponto de vista dos distintos tipos de atores ou agentes socioeconômicos, caracterizados na etapa anterior, quanto do ponto de vista dos interesses da sociedade local.

O processo de elaboração do Plano de Desenvolvimento do APL Celeiro seguiu uma metodologia que considerou e valorizou reflexões e discussões já realizadas pelos atores do Arranjo ao longo de sua trajetória, além da experiência acumulada pela equipe técnica na realização do Plano de Desenvolvimento do APL Pós-colheita Panambi-Condor (BASSO; TRENNEPOHL, 2012). O processo de construção do Plano foi desdobrado em três etapas principais: de diagnóstico, de análise e identificação de temas relevantes e de construção de estratégias e agenda de ações.

No caso específico do APL Celeiro, a etapa de diagnóstico da realidade envolveu a coleta e sistematização de informações obtidas junto aos atores do APL, especialmente de sua governança, bem como a pesquisa de informações secundárias e a montagem de um banco de dados. Além dos contatos com a governança do APL, foram realizadas entrevistas semiestruturadas com representantes de todas as cooperativas do setor lácteo participantes do APL e de 
representantes de algumas agroindústrias familiares de outros segmentos produtivos, também integrados ao APL Celeiro. O contato direto com as cooperativas e agroindústrias familiares privilegiou o conhecimento da história e realidade presente de cada empresa e, principalmente, o levantamento de informações para o cálculo do Valor Bruto da Produção, do Valor Agregado e da Renda de cada estabelecimento individual.

O esforço principal foi direcionado à análise das informações coletadas e elaboração de um diagnóstico atualizado e sintonizado com a leitura e interpretação da realidade feita a partir de observações diretas e de contatos com atores do APL.

A observação da realidade e a construção de estratégias ou planos de desenvolvimento podem ser vistos em diferentes perspectivas. Numa perspectiva, a observação da realidade é condicionada ao sentido das estratégias a serem construídas a partir de um conceito pré-estabelecido sobre o processo de desenvolvimento. Na segunda perspectiva, ocorre o contrário: a construção de estratégias fica condicionada à observação e compreensão da realidade e ao que os atores pretendem fazer de suas vidas. Nesse caso, o conceito de desenvolvimento não necessariamente está dado a priori, presumindo-se a possibilidade de escolhas entre caminhos alternativos (Reis, 2008).

A equipe responsável pelo presente estudo orientou-se pelos pressupostos da segunda alternativa, procurando, mesmo que limitados pelo tempo, compreender a realidade do APL para, a partir desta compreensão, pensar as estratégias e as ações que deveriam constar do Plano de Desenvolvimento. Em todas as etapas do estudo, as sínteses foram sendo elaboradas a partir de discussões sistemáticas feitas no âmbito do grupo, envolvendo o conjunto dos pesquisadores e os técnicos de apoio.

Além das discussões e sistematizações realizadas pela equipe técnica, todas as etapas da elaboração do Plano de Desenvolvimento, incluindo a proposta metodológica, o diagnóstico e a escolha das estratégias e ações, foram discutidas com os atores envolvidos e validadas junto à governança do APL (AGEL, Emater, Amuceleiro, Corede Celeiro, Unijuí, Instituto Federal Farroupilha-Santo Augusto, UERGS - Três Passos, Coordenadoria Regional de Educação de Três Passos) e junto aos técnicos da Agência Gaúcha de Desenvolvimento e Investimento - AGDI da Secretaria de Desenvolvimento e Promoção do Investimento do governo do Estado do Rio Grande do Sul.

Constatou-se que o APL é uma experiência muito rica em termos de organização, que se manifesta pelo reconhecimento por parte da sociedade e do poder público. Existem expectativas muito positivas em relação ao potencial de desenvolvimento do APL que se fundamentam tanto pelo apoio de políticas públicas quanto pela predisposição de envolvimento de uma gama de organizações locais, públicas e privadas, de segmentos econômicos, sociais e políticos. Apesar, entretanto, dos aspectos positivos, existem problemas, debilidades e insuficiências que geram dificuldades ao bom funcionamento do APL. Alguns desses problemas serão destacados a seguir, pois é a partir deles que serão fundamentadas as estratégias e ações que darão base ao Plano de Desenvolvimento objeto deste estudo. 


\section{SÍNTESE DO DIAGNÓSTICO DO APL CELEIRO}

A primeira das dificuldades identificadas no diagnóstico está relacionada à própria formatação do APL Celeiro. A produção de literatura que aborda experiências relacionadas a sistemas locais de produção ou APLs enfatiza as vantagens que muitas empresas, normalmente as de pequeno porte, passam a ter como resultado da sua proximidade espacial. Como destacado por Costa (2012), APL é um instrumento útil para trabalhar com as empresas de menor porte, desde que tomadas em seu conjunto e não das firmas individualmente. Trata-se de um enfoque diferente das ações derivadas do modelo da grande empresa, de cuja liderança se espera a geração de dinamismo econômico.

O diagnóstico realizado na região Celeiro revelou que a interação e a cooperação entre os agentes integrantes do APL Celeiro são fracas. Cotejando o produto da observação do processo real (diagnóstico) com a discussão proposta por Costa (2012), pode-se relacionar a debilidade dos laços sociais entre os atores pertencentes ao APL Celeiro à natureza da sua composição. O APL Celeiro é constituído por um número significativo de agentes, não necessariamente empresas, responsáveis pela produção de uma variedade de produtos com algumas afinidades, mas com outras tantas particularidades. Além dos agricultores familiares, integram o APL as associações, cooperativas e organizações de natureza socioeconômica que não exercem funções técnico-produtivas na cadeia. São agentes situados num território relativamente amplo e heterogêneo com obstáculos diversos para a cooperação ou a ação conjunta.

O que ficou evidente ao longo do processo de realização do diagnóstico é que as relações de cooperação e de confiança são mais frequentes entre grupos de agricultores ou de agroindústrias familiares como estratégia de sobrevivência e reprodução social. Vencida essa primeira necessidade, não necessariamente subsiste o interesse pela cooperação e a opção pela competição com outros grupos e organizações se recoloca em novos patamares. Essas evidências detectadas no diagnóstico levaram a identificar as relações de cooperação e governança como principais dificuldades a serem enfrentadas pelo Plano de Desenvolvimento do APL e a articulação política plural e abrangente como um desafio.

Dificuldades e denúncias de adulteração de produto na cadeia do leite, investigadas pelo Ministério Público e publicadas durante o desenvolvimento do diagnóstico, apontam carências para as quais o APL deveria buscar formas de proteção desta cadeia produtiva, pois envolve diferentes atores. O diagnóstico deixa a percepção de que existe domínio sobre o conhecimento básico e sobre os processos de produção, porém há uma exposição e ausência de controle em diferentes etapas da cadeia, especialmente no campo do transporte e industrialização, demonstrando grande fragilidade. As relações baseadas na desconfiança impedem que o tema seja objetivamente discutido de forma coletiva no âmbito do Arranjo. Isso poderia ser progressivamente superado na medida em que aumentasse o nível de complementaridade entre os participantes do APL.

Constatou-se igualmente que existem fragilidades importantes de impactos ambientais no interior do APL. Está em instalação o Cadastro Ambiental Rural - CAR e os planos de Gestão Integrada de Resíduos Sólidos, devendo consolidar o planejamento e as práticas ambientalmente adequadas para qualificar o APL e o conjunto de seus produtos do ponto de vista sanitário e ambiental. O diagnóstico 
mostrou que existem condições favoráveis para a formação e capacitação dos agentes do APL. Há necessidade de aproximação e apropriação das realidades expressas no diagnóstico, com potencialidade de mobilizar para a qualificação e cooperação entre as cooperativas e associações, bem como as instituições locais e administrações públicas, construindo parcerias para ampliar a qualificação dos dirigentes cooperativos, dos produtores das cadeias e até mesmo de promoção do consumo sustentável.

Por outro lado, o APL pode contar com a participação de várias entidades locais e cooperativas, bem como com instituições de ensino, pesquisa e extensão para enfrentar questões relacionadas aos processos produtivos, organizacionais e de mercado, tanto nos aspectos de estruturação de projetos quanto de cursos de qualificação para atuar no âmbito da cadeia. Quanto à capacidade de investimentos e à disponibilidade de crédito, igualmente observa-se a necessidade de garantir apoio e articulação para diferentes atores do APL. Há concordância de que existem linhas de crédito e disponibilidade de recursos para financiar investimentos, mas muitos ainda têm dificuldades para acesso a crédito, seja por problemas burocráticos e dificuldades de oferecer garantias e mesmo a capacidade de contrair créditos por conta do grau de endividamento.

O APL, em seu conjunto, apresenta reais possibilidades para alcançar melhorias, tanto em qualidade quanto em produtividade, e um grande trunfo para isso está na busca de maior integração entre os integrantes do Arranjo Produtivo. Essas dificuldades poderão ser superadas pela atuação da própria AGEL, bem como pelo dinamismo das articulações que o Arranjo Produtivo possa passar a contar com a atuação da governança, pela amplitude de sua composição, pela responsabilidade que vem demonstrando no processo e pela identidade com as políticas governamentais propostas para o setor, entendendo sua importância para o desenvolvimento local. Com base nesses pontos do diagnóstico sintetizados aqui, apresenta-se, na sequência, algumas estratégias e ações que integram o Plano de Desenvolvimento para o APL Celeiro (Basso \& Trennepohl, 2014).

\section{PROPOSIÇÃO DE ESTRATÉGIAS E AÇÕES DE DESENVOLVIMENTO PARA O APL CELEIRO}

Para fazer frente às dificuldades e problemas diagnosticados, cresce em importância para o plano o conjunto de estratégias e ações definidas para serem desenvolvidas num futuro próximo. Além de caminhar no sentido dos objetivos traçados, as estratégias devem contribuir para a construção da própria identidade deste sujeito (o APL), explicitando seu planejamento. Foram apresentadas seis estratégias e, para cada uma, há uma compreensão muito clara de sua necessidade e da importância de realização de múltiplas ações que possibilitem sua efetividade. Essas estratégias e respectivas ações são detalhadas na sequência.

\subsection{Qualificação da produção agropecuária no Arranjo Produtivo Local}

Ao longo do diagnóstico realizado, foram apontados inúmeros aspectos limitadores da competitividade dos agentes do APL no mercado. Embora muitos desses limitadores estejam relacionados com as condições naturais de solo ou 
topografia, com a estrutura fundiária predominante na região ou com a distância até os principais centros consumidores, aspectos de difícil alteração no âmbito do Plano de Desenvolvimento, foi possível constatar também o potencial de melhoria dos processos produtivos existentes.

Os parâmetros de produção, produtividade, qualidade, custos e rentabilidade existentes no momento do diagnóstico são semelhantes aos níveis estadual e nacional, ou mesmo aos de outras regiões em que ocorrem produções semelhantes. São patamares relativamente baixos e que possibilitam ganhos significativos com a adoção de ações simples e disponíveis no contexto das recomendações técnicas para o setor.

Por tais motivos, o Plano propõe como primeira estratégia a ser estabelecida pelo APL Celeiro a realização de um conjunto de ações no sentido de qualificar a produção realizada pelos agricultores familiares da região. A estratégia implica a realização de amplo debate regional, envolvendo agricultores e técnicos representantes de entidades ligadas às políticas públicas de âmbito municipal, estadual e nacional, à assistência técnica, ao planejamento e ao fomento de inovações e tecnologias de produção. São ações prioritárias: a realização de Seminários Municipais de Desenvolvimento Rural com o objetivo de debater a problemática do setor e identificar possibilidades de desenvolvimento; a proposição de Programas Municipais de Apoio à Agricultura Familiar; ampliar a efetividade dos Serviços de Assistência Técnica e Gerencial aos Agricultores da região mediante integração de esforços e cooperação estratégica e operacional entre as equipes da Empresa de Assistência Técnica e Extensão Rural - Emater, das Secretarias Municipais, das Cooperativas e dos demais Agentes que integram o APL; exigir investimentos na Qualificação da Infraestrutura de Energia Elétrica disponibilizada aos agricultores por parte das empresas concessionárias deste serviço na região; exigir investimentos na Qualificação da Infraestrutura de Transportes disponibilizada aos agricultores por parte das prefeituras e dos governos estadual e federal; gerar apoio técnico-gerencial aos agricultores para o Planejamento Estratégico dos Investimentos Produtivos com vistas à melhoria dos indicadores de Qualidade e Produtividade, ao Aumento de Escala e à Redução dos Custos da Produção Agropecuária.

\subsection{Qualificação dos sistemas de processamento da produção agropecuária}

O aumento do volume e da qualidade da produção agropecuária gera o desafio imediato de ampliar as necessidades de processamento e agregação de valor. A maioria dos produtos, em especial o leite, necessita de processamento para viabilizar sua comercialização. As unidades de processamento existentes no âmbito do APL apresentam pouca capacidade para responder aos novos volumes e, especialmente, aos desafios de qualidade exigidos pelo mercado e mais rentáveis para a cadeia produtiva. Trata-se, portanto, de uma estratégia importante desse plano o fomento à Qualificação dos Sistemas de Processamento da Produção Agropecuária Regional. É necessário apoiar as iniciativas das Agroindústrias Familiares existentes na região, bem como a realização de parcerias com cooperativas ou empresas com competência para receber, processar e comercializar a produção do APL. 
São ações prioritárias: ampliar a efetividade dos Serviços de Assistência Técnica e Gerencial para as Agroindústrias Familiares; proporcionar apoio técnicogerencial para a elaboração de projetos e apoio político-institucional para obtenção de recursos e licenciamentos pertinentes à instalação de novas unidades de processamento agroindustrial; fomentar a realização de parcerias com Indústrias Processadoras de Alimentos com capacidade diferenciada; agilizar os Sistemas de Licenciamento e de Inspeção da Produção das Agroindústrias Familiares da região de modo a viabilizar a comercialização dos produtos em mercados mais amplos e atrativos; proporcionar apoio técnico-gerencial aos proprietários de agroindústrias para o Planejamento Estratégico dos Investimentos Produtivos, visando à melhoria dos indicadores de Qualidade e Produtividades, ao Aumento de Escala e Redução dos Custos da Produção.

\subsection{Articulação de parcerias de comercialização}

O Arranjo Produtivo é resultado do esforço dos agricultores familiares que, no enfrentamento de suas dificuldades, criaram associações e cooperativas para assumir tarefas e funções que não poderiam cumprir individualmente. Seria um erro atribuir às entidades recém-criadas a responsabilidade pela execução de todas as tarefas necessárias. Mais plausível seria concentrar os esforços das cooperativas e associações nas funções que podem cumprir com êxito e estabelecer parcerias entre elas e com outras empresas para as atividades mais complexas ou para as quais não foi possível gerar competências até o momento.

A articulação de parcerias para realizar a comercialização da produção agroindustrial é uma estratégia importante para o APL na medida em que permite dinamizar os fluxos de escoamento de mercadorias e obtenção de renda em escala ampliada e, sobretudo, possibilita participar de experiências bem-sucedidas e gerar novas competências para o futuro. São ações prioritárias: estreitar relações entre os elos da cadeia produtiva do leite já que as cooperativas de produtores não têm condições de assumir diretamente todas as funções do processo de comercialização da produção de seus associados. Existem empresas com capacidades distintas (coleta, processamento, distribuição, etc.) dispostas a firmar parcerias comerciais de médio prazo, ampliando a estabilidade e a sustentabilidade da cadeia produtiva; fazer negociação com fornecedores de Insumos, Máquinas e Equipamentos e articulação de compras conjuntas entre as cooperativas e a disponibilização destes insumos aos seus associados, poderão representar ganhos importantes em termos de qualidade e custo de produção; negociar com distribuidores dos Produtos do APL. A comercialização da produção agroindustrial está fortemente restrita aos mercados locais e regionais, enquanto as melhores oportunidades estão nos centros urbanos de maior porte e mais distantes; planejar as Ações de Mercado. As características comuns da produção agroindustrial possibilitam a organização e ações coletivas de promoção e conquista de mercado. Para potencializar as ações é importante elaborar um Plano de Marketing para o APL.

\subsection{Ampliação do número de produtores participantes}

Os agentes que compõem o APL têm uma boa representatividade regional, mas não cobrem a totalidade da população-alvo. Existem muitos agricultores que 
podem ser integrados às cooperativas existentes e, especialmente, é necessário criar alternativas para cobrir espaços em que não existem tais entidades. Há locais municípios por inteiro - em que não há cobertura pelas cooperativas ou associações do APL. Em alguns casos, as cooperativas existentes encerraram suas atividades e, em outros, não houve iniciativas bem-sucedidas de organização das mesmas.

A ampliação do número de agricultores familiares participantes do APL é uma estratégia importante para consolidar a representatividade social e política do APL, bem como para gerar ganhos de escala e capacidade econômica pelo volume de produção que representa. São ações prioritárias: fomentar o surgimento de novas Associações e Cooperativas de produtores, pois ainda existe um número significativo de agricultores familiares na região que não está organizado em associação ou cooperativa para participar dos avanços conquistados pela ação do APL; estimular o ingresso de novos associados nas cooperativas, pois uma parcela dos agricultores familiares não organizados é domiciliada dentro das áreas de abrangência das cooperativas já existentes; atrair outros agentes da cadeia para o APL e a ampliação do número de agentes articulados no arranjo representa um potencial a ser explorado para consolidar sua representatividade econômica, social e política; formalizar parcerias de cooperação técnica, comercial e política e ampliar os laços de integração e cooperação entre os agentes do APL é importante para consolidar a unidade e a consistência da ação conjunta.

\subsection{Formação e capacitação técnica, gerencial e política}

Uma leitura atenta da realidade regional permite apontar como elemento estratégico para o Plano de Desenvolvimento do APL a capacitação técnica, gerencial e política dos agricultores familiares. Como agentes fundantes do APL, os agricultores possuem limitações oriundas de seu baixo grau de escolaridade e, consequentemente, maiores dificuldades para incorporar inovações tecnológicas, gerenciar suas unidades de produção e suas entidades cooperativas ou compreender a dimensão política de seu envolvimento nas cooperativas e no APL.

As entidades de apoio do APL no campo educacional têm possibilidade para ofertar cursos e programas de formação e capacitação, nos mais diversos campos, para agricultores, dirigentes e funcionários das cooperativas e associações. São ações prioritárias: realizar cursos e programas de formação técnica para agricultores, o que compreende um amplo leque de necessidades e potencialidades a ser contemplado, desde os procedimentos básicos de limpeza e higiene das instalações e equipamentos utilizados, o manejo dos animais, o cultivo da terra, até o acesso às inovações tecnológicas e a redução da penosidade, periculosidade ou insalubridade de certas tarefas que compõem o trabalho dos agricultores familiares; realizar programas de capacitação gerencial para agricultores e dirigentes e entidades associativas, pois os desafios das agroindústrias envolvem situações de mercado e comercialização, de crédito e financiamento dos investimentos, de planejamento de médio e longo prazo, de gestão das unidades de produção e também das cooperativas e outras organizações criadas com o objetivo de gerar soluções coletivas; realizar programas de capacitação econômica, financeira e mercadológica para dirigentes e funcionários das cooperativas e associações, pois as cooperativas e associações são organizações criadas para enfrentar os desafios do mercado, da comercialização ou do relacionamento econômico com o contexto 
externo e precisam estar preparadas para cumprir com suas responsabilidades; realizar programas de formação política sobre associativismo e cooperativismo na região, pois, tão importante quanto a formação instrumental, técnica e gerencial, é a formação política dos agentes do APL para fortalecer a compreensão do que representa o associativismo e o cooperativismo como instrumentos para impulsionar o desenvolvimento regional. É certo que os cursos e programas de formação política devem estar articulados com conteúdo de formação técnica e gerencial, pois se trata de construir caminhos alternativos de futuro cuja possibilidade de sucesso implica a constituição de competências nas três dimensões.

\subsection{Ampliação da capacidade de cooperação e governança}

Foi possível constatar no diagnóstico que o trabalho realizado pelo APL está sendo de grande importância, em especial para a população ameaçada de exclusão social. O alcance e o impacto das ações do APL, entretanto, ainda são limitados, em comparação com as necessidades da região e com as potencialidades que ele representa. As expectativas em relação às possibilidades de alcançar resultados positivos por intermédio do APL estão presentes na população da região. $\mathrm{A}$ experiência precisa, no entanto, ser consolidada ampliando a capacidade de cooperação entre os agentes que compõem o APL e a capacidade de governança interna e de representatividade diante de outras entidades.

Essa sexta estratégia tem um caráter sistematizador das demais, pois sua efetivação depende, em grande medida, da capacidade do APL Celeiro para colocar em prática o Plano de Desenvolvimento elaborado e efetivar, com resultados expressivos, as ações propostas e aprovadas pelo Conselho de Governança. Muito mais do que ações específicas ou complementares às demais, esta estratégia se efetiva por meio das ações que forem realizadas e do caráter dos resultados alcançados. Trata-se de construir referências pela experiência acumulada ao longo do trabalho.

São ações prioritárias: realizar um trabalho de conscientização sobre cooperativismo e suas potencialidades, já que o papel da AGEL, na condição de coordenadora executiva do APL, é de fundamental importância para o sucesso do plano e sua efetivação se constituirá em processo de vivência das reais potencialidades do cooperativismo para gerar soluções aos problemas do desenvolvimento; ampliar a cooperação e parcerias entre as cooperativas, estimulando a cooperação e a realização de parcerias entre os agentes do APL, em especial as cooperativas, é de grande importância para tornar mais efetivos os trabalhos, mas também para dar coerência ao discurso político pelo associativismo; articular com instâncias dos poderes públicos municipais e regionais e estabelecer um diálogo produtivo e a definição de ações convergentes e compartilhadas para potencializar os resultados do esforço empreendido; instituir um fórum de reflexão e debates sobre o desenvolvimento regional com a realização de seminários de debates sobre o desenvolvimento em cada um dos 21 municípios da região, o que certamente suscitará a identificação de muitos temas relevantes com abrangência supralocal. Além de apontar caminhos ou alternativas para as políticas públicas de apoio à agricultura familiar das prefeituras, esse debate amplo e plural poderá contribuir para a constituição de uma pauta de debates para a região. Além de 
identificar temas ou problemas para compor uma pauta, terá como desafio mobilizar segmentos sociais, entidades e organizações numa perspectiva comum. Não há dúvidas quanto à necessidade do diálogo qualificado e permanente com as entidades existentes na região, com potencial de contribuição no debate sobre o desenvolvimento regional em suas múltiplas nuances.

\section{CONSIDERAÇÕES FINAIS}

O planejamento estratégico abrange a construção da identidade do APL, a definição da missão e dos objetivos institucionais e desenvolve-se numa perspectiva de longo prazo, partindo de uma abordagem global que envolve a organização como um todo integrado de recursos, capacidades e potencialidades. Para que obtenha efetividade, precisa ser implementado nas distintas instâncias envolvidas no APL, onde acontece a execução das tarefas.

Considerando que o alcance do Plano de Desenvolvimento proposto é correspondente ao planejamento estratégico, global do arranjo produtivo, torna-se importante apontar os Planos Táticos necessários à plena realização das estratégias definidas e possibilitando alcançar os objetivos estratégicos escolhidos. Sua elaboração exigirá esforço adicional de estudo e de articulação institucional que poderá ser levada a cabo pela governança operacional do APL no desenvolvimento de suas atividades.

A razão de ser de um APL é exatamente a possibilidade de representar diferenciais de competitividade para as empresas participantes, fruto da proximidade, integração e cooperação entre elas e com as entidades de apoio. Essa é a razão para escolher essa estratégia como sistematizadora das demais. 0 desenvolvimento do APL implica em ampliar as ações próprias de sua natureza e que lhe permitam aprofundar sua identidade. Foi sugerida a constituição de uma equipe multiprofissional para assumir a governança operacional e a tarefa de identificar grupos de interesse e pontos de convergência para articular ações conjuntas entre empresas, cooperativas e associações capazes de gerar resultados significativos aos cooperantes.

\section{REFERÊNCIAS}

BASSO, D.; MUENCHEN, J. V. Contribuição de Diferentes Tipos de Empresas Industriais para o Desenvolvimento Local: o caso do município de ljuí/RS.

Desenvolvimento em Questão. ljuí, Editora Unijuí. V. 4, N. 7, , p. 95-125, Jan-Jun 2006.

BASSO, D. Fundamentos Teóricos e Procedimentos Metodológicos para a Análise de Processos Reais de Desenvolvimento. In: SIEDENBERG, D. R. (Org). 0

desenvolvimento sob múltiplos olhares. Ijuí, Ed. Unijuí, 2012, p. 101-137.

BASSO, D.; TRENNEPOHL, D. (Org). Planejamento estratégico de arranjos produtivos locais: o plano de desenvolvimento do APL metalmecânico pós-colheita - Panambi e Condor 2012 - 2022. ljuí, Ed. Unijuí, 2012, 208 p. (coleção gestão e desenvolvimento). 
BASSO, D.; TRENNEPOHL, D. (Org). Planejamento estratégico de arranjos produtivos locais: plano de desenvolvimento do APL agroindústria familiar da região celeiro 2014 - 2020. ljuí, Ed. Unijuí, 2014, 344 p. (coleção gestão e desenvolvimento).

BECATTINI, G. Italian Industrial Districts: Problems and Perspectives. International Studies of Management and Organization. Vol. 21, , p. 83-90, Nº1, 1991.

BUSTELO, E. Planejamento e Política Social: a dialética do possível. In: BROMLEY, R; BUSTELO, E. (org.) Política x Técnica no Planejamento: perspectivas críticas. São Paulo: Brasiliense/UNICEF, 1982.

CASTILHOS, C. C. Sistemas locais de produção do RS: reflexões sobre seus limites e possibilidades enquanto política pública. In: CASTILHOS, C. C. (Coord.). Programa de apoio aos sistemas locais de produção: a construção de uma política pública no RS. Porto Alegre: FEE / SEDAI, 2002.

COSTA, A. B. da. O papel dos Arranjos Produtivos Locais, das grandes empresas e das cadeias produtivas no desenvolvimento econômico. In: BREITBACH, A. C. de M. (Org.). Os desafios do desenvolvimento local. Porto Alegre: FEE, 2012. p. 8-25.

DEMO, P. Participação é Conquista. 2 ed. São Paulo: Cortez/Autores Associados, 1993.

GROSS, B. O planejamento numa era de revolução social. In: BROMLEY, R., BUSTELO, E (org.). Política x Técnica no Planejamento: perspectivas críticas. São Paulo: Brasiliense/UNICEF, 1982.

LASTRES, H.; CASSIOLATO, J. E. Prefácio. In: LASTRES, M. M. H.; CASSIOLATO, J. E.; ARROIO, A. (Org). Conhecimento, Sistemas de Inovação e Desenvolvimento. Rio de Janeiro, Ed. UFRJ/Contraponto, 2005, p. 9-13.

MATUS, C. O método PES: entrevista com Matus / Franco Huertas. Tradução de Giselda Barroso Sauveur. São Paulo: Fundap. 1996.

MUCKE, N. Apresentação pela AGDI. In: BASSO, D.; TRENNEPOHL, D. (Org). Planejamento estratégico de arranjos produtivos locais: o plano de desenvolvimento do APL metalmecânico pós-colheita - Panambi e Condor 2012 2022. ljuí, Ed. Unijuí, 2012, p 9-10.

REIS, M. C. dos. O debate desenvolvimentista e as representações do desenvolvimento local. In: SECRETO, M. V.; CARNEIRO, M. J.; BRUNO, R. (Org). o Campo em Debate: terra, homens, lutas. Rio de Janeiro, Mauad X; Seropédica, EDUR, 2008, p. 175-197.

SILVA NETO, B. Análise-Diagnóstico de Sistemas Agrários: uma interpretação baseada na Teoria da Complexidade e no Realismo crítico. Desenvolvimento em Questão. ljuí, Ed. Unijuí, ano 5, n. 9, p. 33-58, 2007. 
SILVA NETO, B.; BASSO, D. A Ciência e o Desenvolvimento Sustentável: para além do Positivismo e da Pós-modernidade. Ambiente \& Sociedade, Campinas, vol. XIII, n. 2, p. 315- 329, jul.-dez. 2010.

TATSCH, A. L. et al. Política para APLS no RS: critérios e arranjos selecionados para apoio. Ensaios FEE, Porto Alegre, v. 31, Número Especial, p. 703-740, jun. 2011.

TAVARES, M. C. Planejamento estratégico: a opção entre sucesso e fracasso empresarial. São Paulo: Harbra, 1991.

TRENNEPOHL, D. Projetos de Desenvolvimento. In: SIEDENBERG, D. R. (Org). 0 desenvolvimento sob múltiplos olhares. Ijuí, Ed. Unijuí, 2012, p. 369-392.

David Basso. Doutor em Desenvolvimento, Agricultura e Sociedade pela Universidade Federal Rural do Rio de Janeiro (UFRRJ). Professor da Universidade Regional do Noroeste do Estado do Rio Grande do Sul (UNIJUI). davidbasso@unijui.edu.br

Dilson Trennepohl. Doutor em Desenvolvimento Regional pela Universidade de Santa Cruz do Sul (UNISC). Professor da Universidade Regional do Noroeste do Estado do Rio Grande do Sul (UNIJUI). dilson@unijui.edu.br

José Valdemir Muenchen. Mestre em Economia Aplicada pela Escola Superior de Agricultura Luiz de Queiroz (Esalq/USP). Doutorando em Desenvolvimento Regional pela Universidade Regional do Noroeste do Estado do Rio Grande do Sul (UNIJUI). josevaldemirmuenchen@hotmail.com

Tiago Reginaldo Zagonel. Mestre em Desenvolvimento pela Universidade Regional do Noroeste do Estado do Rio Grande do Sul (UNIJUI). Doutorando em Agronegócios pela Universidade Federal do Rio Grande do Sul (UFRGS). tiagozagonel@hotmail.com 